\title{
Research on Hydrometallurgical Processing of Gold-Concentrate of Jamgyr Deposit
}

\author{
Lyutsiya M. Karimova*, \\ Dmitry V. Zakharyan and Yaroslav E. Agapitov \\ LLP "KazHydroMed" \\ Karaganda, Republic of Kazakhstan
}

Received 15.12.2020, received in revised form 12.02.2021, accepted 21.03.2021

\begin{abstract}
Laboratory studies have been carried out on the processing of gold-bearing concentrate from the "Jamgyr" deposit using the JIN CHAN reagent. The influence of the concentration JIN $\mathrm{CHAN}$, the duration of leaching, the temperature of the solution were studied. As a result of research, the extraction of gold and silver into solution using cyanide-free technology was 97,5\% and 96\%, respectively. The processing of the obtained solutions by the method of sorption was carried out on the MA940BG (gold) ion-exchange resin with the extraction of target components from the solution into the ion-exchange resin: $\mathrm{Au}-100,0 \%, \mathrm{Ag}-77,5 \%$.
\end{abstract}

Keywords: gold, concentrate, leaching, ecological reagent, sorption.

Citation: Karimova L.M., Zakharyan D.V., Agapitov Ya.E. Research on hydrometallurgical processing of gold-concentrate of jamgyr deposit, J. Sib. Fed. Univ. Eng. \& Technol., 2021, 14(2), 166-174. DOI: 10.17516/1999-494X-0297

\section{Исследования по гидрометаллургической переработке золотосодержащего концентрата месторождения «Джамгыр»}

\author{
Л.М. Каримова, Д.В. Захарьян, Я.Е. Агапитов \\ ТОО «КазГидроМедь» \\ Республика Казахстан, Караганда
}

\footnotetext{
Аннотация. Проведены лабораторные исследования по переработке золотосодержащего концентрата месторождения «Джамгыр» с помощью реагента JIN CHAN (Цзинь Чань). Изучено влияние концентрации JIN CHAN, продолжительность выщелачивания, температура раствора. В результате исследований извлечение золота и серебра в раствор по бесцианидной технологии

(C) Siberian Federal University. All rights reserved

This work is licensed under a Creative Commons Attribution-Non Commercial 4.0 International License (CC BY-NC 4.0).

* Corresponding author E-mail address: lutsia.08@mail.ru
} 
составило 97,5 и 96 \% соответственно. Переработку полученных растворов методом сорбции проводили на ионообменной смоле MA940BG (gold), извлечение целевых компонентов из раствора в ионообменную смолу составило: $\mathrm{Au}-100,0 \%, \mathrm{Ag}-77,5 \%$.

Ключевые слова: золото, концентрат, выщелачивание, экологический реагент, сорбция.

Цитирование: Каримова, Л.М. Исследования по гидрометаллургической переработке золотосодержащего концентрата месторождения «Джамгыр» / Л.М. Каримова, Д.В. Захарьян, Я.Е. Агапитов // Журн. Сиб. федер. ун-та. Техника и технологии, 2021, 14(2). С. 166-174. DOI: 10.17516/1999-494X-0297

\section{Введение}

Основным реагентом в гидрометаллургии получения золота и серебра из руд является цианид натрия, который применяется уже более 100 лет. Цианистый процесс обеспечивает извлечение порядка 80-90 \% золота и серебра. Этот способ обладает существенными технологическими и экономическими преимуществами по сравнению с прочими металлургическими технологиями $[1,2]$.

Однако цианид относится к категории сильнодействующих ядовитых веществ, и его применение сопровождается большим объемом комплексных мероприятий: обеспечение безопасности обслуживающего персонала, обезвреживание цианидов в хвостах, экологические требования при складировании отходов цианирования. Это все дополнительные затраты, ухудшающие экономику процесса [3-8].

В связи с этим ведутся интенсивные работы по изучению возможностей замены цианидов другими альтернативными растворителями. В настоящее время известны альтернативные выщелачивающие системы, способные переводить золото и серебро в растворимое состояние. Наиболее известны из них тиомочевина, тиосульфаты натрия и аммония, галоиды (хлор, бром, йод) [5-9]. Тем не менее ни один из технологических вариантов с использованием нецианистых растворителей золота и серебра пока не может претендовать на роль универсального гидрометаллургического процесса, каковым в настоящее время является цианирование $[3,10]$.

Опубликована информация, что в Китае запатентован новый экологически чистый реагент для выщелачивания золота и серебра без цианида. Реагент представляет собой химическую смесь, состоящую из натриевой соли, полимеризованного цианамида натрия, щелочного тиокарбамида и стабилизатора. Он изготовлен из обычных химических материалов, таких как мочевина, каустическая сода, карбонат натрия и сульфид натрия, смешанных с подходящим катализатором [10, 11].

Многочисленными исследованиями установлено, что растворение золота в цианистых растворах в присутствии кислорода протекает по следующей реакции:

$$
2 \mathrm{Au}+4 \mathrm{NaCN}+\mathrm{O}_{2}+2 \mathrm{H}_{2} \mathrm{O}=2 \mathrm{NaAu}(\mathrm{CN})_{2}+2 \mathrm{NaOH}+\mathrm{H}_{2} \mathrm{O}_{2},
$$

золотоцианистый натрий диссоциирует на ионы:

$$
\mathrm{Na}(\mathrm{AuCN})_{2}=\mathrm{Na}^{+}+\left[\mathrm{Au}(\mathrm{CN})_{2}\right]^{-} \text {. }
$$

Таким образом, золото в растворе находится в составе комплексного цианистого иона $\left[\mathrm{Au}(\mathrm{CN})_{2}\right]^{-}$. Согласно современным представлениям процесс растворения золота в цианистых растворах электрохимический и подчиняется общим закономерностям электрохимической коррозии металлов [12, 13].

$$
-167-
$$


Важным предметом и направлением исследований в горнодобывающей и металлургической сфере является поиск нового выщелачивающего средства для золота вместо высокотоксичного цианида $[2,10,11]$.

В целях разработки промышленной безопасной технологии выщелачивания золота и серебра с помощью экологически чистого выщелачивающего препарата вместо традиционного цианирования были изучены факторы, влияющие на процесс выщелачивания с помощью реагента JIN CHAN («Цзинь Чань»).

Реагент марки JIN CHAN - экологически чистый заменитель цианида, предназначен для ускорения процесса выщелачивания золота и серебра из руд и концентратов с большим содержанием серы, мышьяковистых, сернистых и окисленных руд и связывания металла в пульпе.

\section{Экспериментальная часть}

Для проведения исследований по выщелачиванию использовали концентрат из месторождения «Джамгыр» (Казахстан), его химический состав приведен в табл. 1.

Таблица 1. Содержание основных компонентов в черновом концентрате

Table 1. Content of main components in rough concentrate

\begin{tabular}{|c|c|c|c|}
\hline Компоненты & Содержание, $\%$ & Компоненты & Содержание, $\%$ \\
\hline $\mathrm{Au}, \Gamma / \mathrm{T}$ & 62,2 & $\mathrm{~Pb}$ & 0,25 \\
\hline $\mathrm{Ag}, \mathrm{\Gamma} / \mathrm{T}$ & 51,41 & $\mathrm{As}, \Gamma / \mathrm{T}$ & 93,86 \\
\hline $\mathrm{Cu}$ & 0,11 & $\mathrm{Al}$ & 8,07 \\
\hline $\mathrm{Fe}$ & 1,58 & $\mathrm{Si}$ & 26,4 \\
\hline $\mathrm{Zn}$ & 0,039 & $\mathrm{~S}$ & 1,43 \\
\hline
\end{tabular}

Исследования проводили в термостатированном реакторе марки «Minni-50-1» с перемешиванием (170 об/мин), изучали влияние концентрации реагента JIN CHAN в интервале от 3,3 до 46,66 г/дм ${ }^{3}$, продолжительности выщелачивания 1-5 ч и температуры раствора 30-50 ${ }^{\circ} \mathrm{C}$ при отношении Ж:Т-3:1, в раствор вводили Са О.

\section{Результаты и их обсуждение}

Условия и полученные результаты по влиянию концентрации реагента JIN CHAN, продолжительности и температуры выщелачивания на извлечение золота, серебра и меди в раствор представлены в табл. 2.

Как демонстрируют данные рис. 1, концентрация реагента оказывает определенное влияние на извлечение компонентов в раствор.

При малой концентрации 3,3 г/дм³ извлечение золота и серебра составило 93,5, 93,14 \% соответственно. Вероятно, нехватка выщелачивающего агента приводит к образованию поверхностных пленок, затрудняющих доступ к непрореагировавшим частицам. 


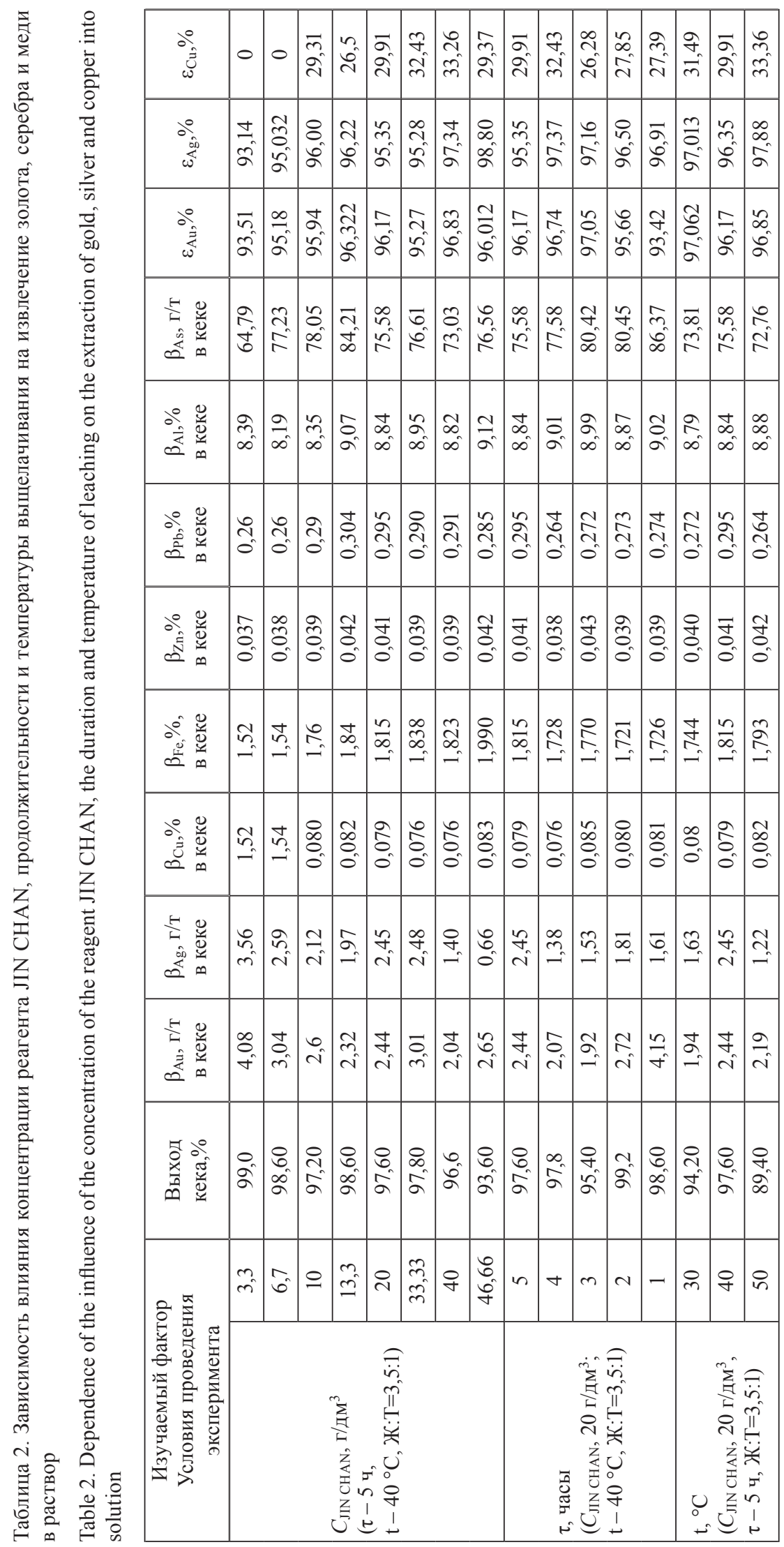




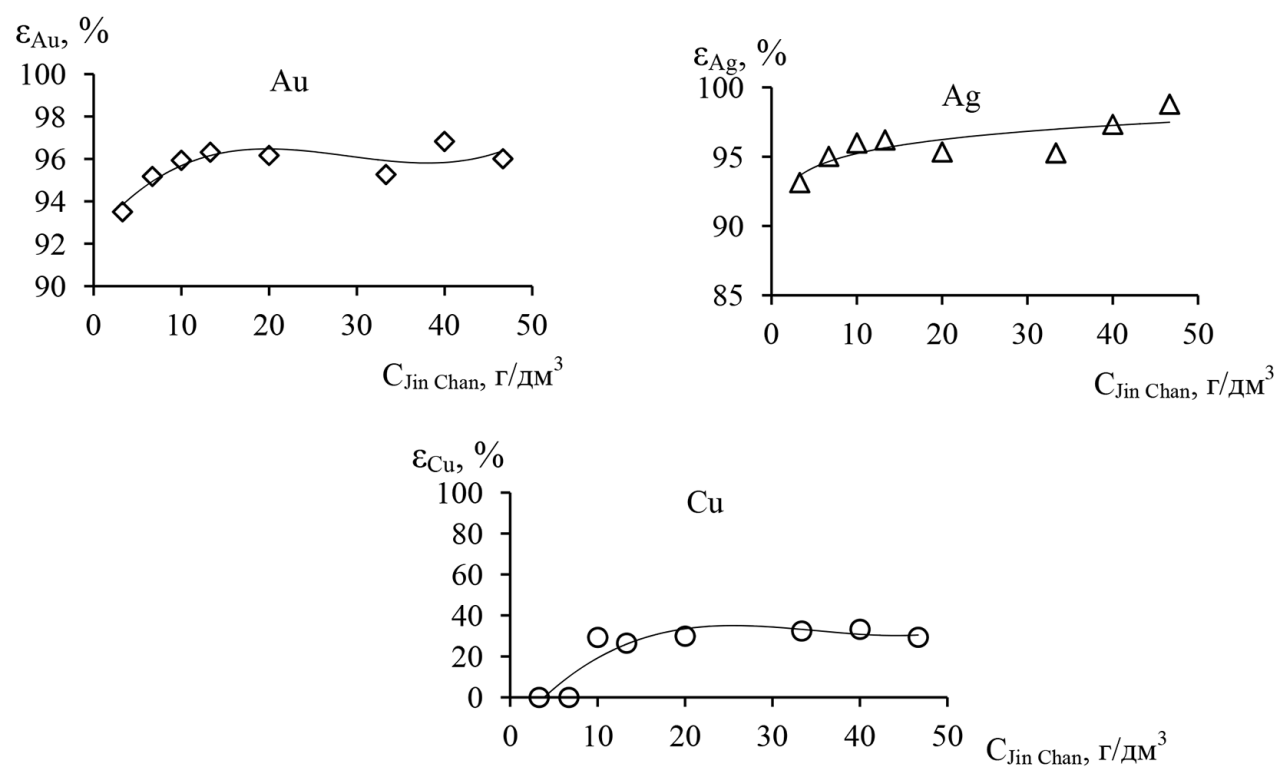

Рис. 1. Влияние концентрации реагента JIN CHAN на извлечение золота, серебра и меди в раствор

Fig. 1. Effect of the concentration of the JIN CHAN reagent for the extraction of gold, silver and copper into solution

Концентрация реагента более 5 г/дм³ приводит к повышению показателей извлечения. Дальнейшее повышение концентрации реагента не оказывает влияние на извлечение золота и серебра. В результате экспериментов определена оптимальная концентрация реагента JIN CHAN - 10-12 г/дм ${ }^{3}$, при этом извлечение компонентов в раствор составило: $\mathrm{Au}-96,0 \%$; $\mathrm{Ag}-$ $96,0 \% ; \mathrm{Cu}-29,31 \%$.

Изучено влияние температуры раствора в интервале $30-50{ }^{\circ} \mathrm{C}$ на извлечение ценных компонентов в следующих условиях:

- концентрация реагента JIN CHAN - 20 г/дм³;

- отношение Ж:Т=3:1;

- продолжительность выщелачивания - 5 ч.

Графики частных зависимостей влияния температуры раствора $\left(\mathrm{t},{ }^{\circ} \mathrm{C}\right)$ на извлечение золота (а), серебра (б) и меди (в) в раствор представлены на рис. 2 и в табл. 2.

Из литературных источников известно [5], что при цианировании повышение температуры имеет двоякое воздействие: с одной стороны, интенсивность растворения золота несколько возрастает за счет повышения скорости химического взаимодействия и в некоторой степени увеличения скорости диффузии реагентов, с другой-также увеличивается скорость протекания побочных реакций, что ведет к загрязнению раствора и перерасходу реагента. В свою очередь, снижается растворение кислорода в растворе, что вызывает разложение цианидов. Повидимому, эти особенности проявляются и в данном случае.

С ростом температуры от 30 до $50^{\circ} \mathrm{C}$ извлечение золота, серебра в раствор увеличивается, что обусловлено увеличением скорости диффузии. При этом извлечение ценных компонентов в исследуемом интервале повышается: $\mathrm{Au}-97,0 \%$; $\mathrm{Ag}-97,0 \%$; $\mathrm{Cu}-31,4 \%$. 


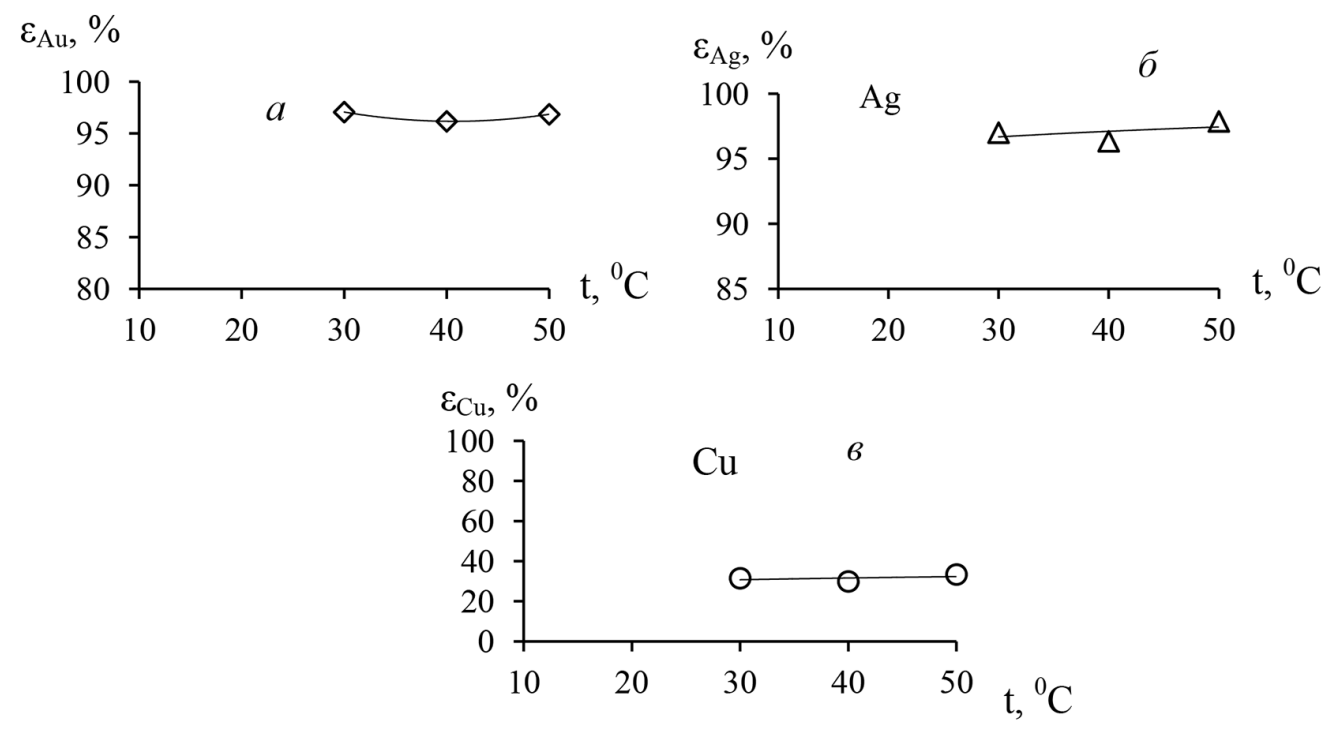

Рис. 2. Зависимости влияния температуры раствора на извлечение золота (а), серебра (б) и меди (в) в раствор

Fig. 2. Dependences of the influence of the temperature of the solution for the extraction of gold (a), silver (б) and copper (в) into solution

Влияние продолжительности выщелачивания изучено в интервале от 1 до 5 ч на извлечение золота, серебра и меди в раствор при следующих условиях:

- отношение Ж:T=3:1;

- температура (t) $40{ }^{\circ} \mathrm{C}$;

- концентрация реагента JIN CHAN 20 г/дм³.

Результаты проведенных исследований представлены в табл. 2 и на рис. 3.

Результаты экспериментов (табл. 2) показывают, что с увеличением продолжительности выщелачивания с 1 до 3 ч извлечение ценных компонентов возрастает и далее практически не меняется. Таким образом, наибольшая скорость и полнота растворения золота и серебра достигается при продолжительности 3 ч; большая скорость растворения серебра в начальный момент (первые 2-3 ч) объясняется взаимодействием реагента JIN CHAN с минералом, в котором содержится почти 50 \% всего серебра, находящегося в концентрате.

Аналогично проведены исследования по выщелачиванию золота и серебра из концентрата «Джамгыр» с использованием цианида натрия. Исследования проводили при следующих условиях:

- отношение Ж:Т=3:1;

- температура (t) $40{ }^{\circ} \mathrm{C}$;

- продолжительность 4 ч.

Концентрацию цианида натрия задавали в интервале 3,3 и 6,7 г/дм³.

Условия и полученные результаты представлены в табл. 3.

Согласно полученным данным, выщелачивание с использованием реагента JIN CHAN обеспечивает сопоставимые с процессом цианирования значения извлечения золота и серебра 


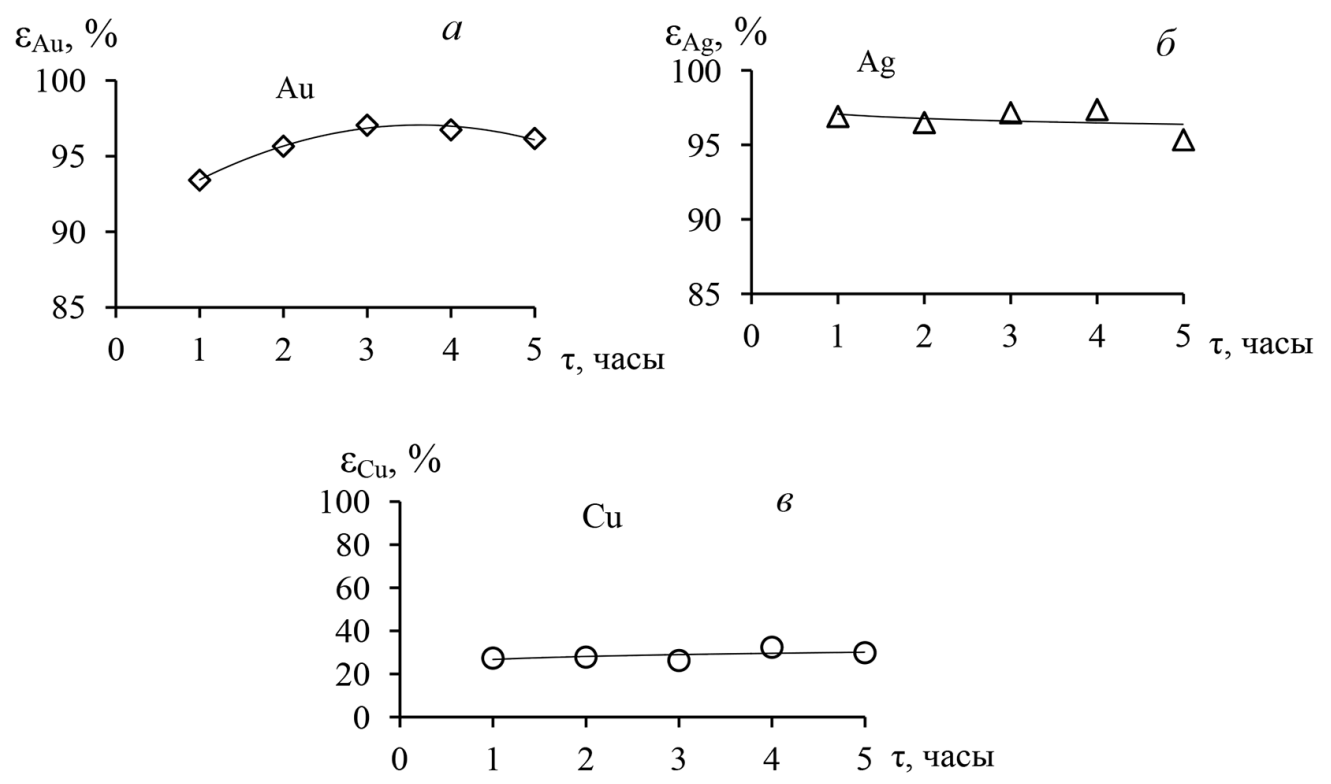

Рис. 3. Зависимости по влиянию продолжительности выщелачивания на извлечение золота (a), серебра (б) и меди (в) в раствор

Fig. 3. Dependences on the effect of leaching duration on the extraction of gold (a), silver (б) and copper (в) into solution

Таблица 3. Зависимость извлечения золота, серебра и меди в раствор от концентрации цианистого натрия Table 3. Dependence of the extraction of gold, silver and copper into solution on the concentration of sodium cyanide

\begin{tabular}{|c|c|c|c|c|c|c|c|c|c|c|c|}
\hline \multirow{2}{*}{$\mathrm{C}_{\mathrm{NaCN}}$} & \multirow{2}{*}{$\begin{array}{c}\text { Выход } \\
\text { кека, \% }\end{array}$} & \multicolumn{6}{|c|}{ Содержание в кеке } & \multirow{2}{*}{$\varepsilon_{\mathrm{Au}}, \%$} & $\varepsilon_{\mathrm{Ag}}, \%$ & $\varepsilon_{\mathrm{Cu}}, \%$ \\
\hline 3,3 & 99,0 & 3,92 & 2,7 & 0,079 & 1,67 & 0,036 & 0,253 & 8,85 & 93,76 & 94,8 & 28,9 \\
\hline 6,7 & 99,0 & 4,3 & 1,8 & 0,075 & 1,53 & 0,047 & 0,240 & 8,53 & 93,15 & 96,53 & 32,5 \\
\hline
\end{tabular}

в раствор. По золоту, сучетом максимальной положительной погрешности, извлечение составляет не менее 97,5\%. Указанное позволяет рекомендовать данный реагент для использования в процессах извлечения золота и серебра из концентрата месторождения «Джамгыр».

Сорбционное извлечение золота и серебра из раствора выщелачивания проводили на ионообменной смоле MA940BG (gold).

Сорбционный каскад представляет собой две последовательно соединенные колонки (1-я - на насыщение; 2-я - на проскок) в следующих условиях:

- удельный объем сорбционной колонны - 0,18 дм³;

- скорость сорбции - 7,5 уд. об/ч или 1,35 дм³/ч;

- направление продуктивного раствора снизу-вверх;

- температура комнатная.

Для контроля степени насыщения ионита в процессе сорбции каждый час проводился отбор проб раствора после прохождения каскада. 
После окончания процесса сорбции в каскад дозирующим насосом подавалась вода для промывки ионообменной смолы.

Водная промывка проводилась в следующих условиях:

- скорость промывки - 7,5 уд. об/ч или 1,35 дм³/ч;

- объем промывной воды - 4 уд. об или 0,72 дм³ $^{3}$;

- температура комнатная.

После водной промывки из 1-й колонны каскада было отобрано $10 \mathrm{~cm}^{3}$ смолы для проведения химического анализа.

Насыщенный сорбент направляли на десорбцию золота и серебра сернокислым раствором тиомочевины $[14,15]$.

На основании полученных данных в процессе сорбции извлечение целевых компонентов из раствора в ионообменную смолу составило: $\mathrm{Au}-100,0 \%, \mathrm{Ag}-77,5 \%$.

\section{Заключение}

Проведены лабораторные исследования по переработке золотосодержащего концентрата месторождения «Джамгыр». Изучали влияние концентрации реагента JIN CHAN в интервале от 3,3 до 46,66 г/дм³; продолжительность выщелачивания - от 1 до 5 ч; температура раствоpa $30-50{ }^{\circ} \mathrm{C}$. В результате проведенных экспериментов достигнуты показатели по извлечению в раствор по бесцианидной технологии:

- $\mathrm{Au}-97,5 \%$;

- $\mathrm{Ag}-96,0 \%$.

Переработка полученных растворов методом сорбции на активированный уголь или ионообменную смолу позволит получить сплав Доре с извлечением золота и серебра не менее 95 \% для последующего аффинажа.

\section{Список литературы / References}

[1] Лодейщиков В.В. Извлечение золота из упорных руд и конщентратов. М.: Недра, 1968. 204 с. [Lodeyshchikov V. V. Extraction of gold from refractory ores and concentrates. Moscow, Nedra, 1968. 204 p. (in Russian)]

[2] Верхозин С.С. Новые нецианистые реагенты для выщелачивания золота производства КНР. Золотодобыча, 2016, 215. https://zolotodb.ru/article/11540 [Verkhozin S. S. New Non-Cyanide Reagents For Leaching Gold Produced In China. Zolotodobycha, 2016, 215. https://zolotodb.ru/article/11540 (in Russian)]

[3] Барченков В.В., Кудияров Н.Ю. Опыт применения в Китае нецианистого реагента Flotent Gold SC570 для выщелачивания золота из руд. Золотодобыча, 2016, 215. https://zolotodb.ru/article/11546. [Barchenkov V. V., Kudiyarov N. Yu. Experience of using non-cyanide reagent Flotent Gold SC570 for leaching gold from ores in China. Gold mining, 2016, 215. https://zolotodb.ru/article/11546 (in Russian)]

[4] Хуан Лихуан. Техника добычи золота и серебра. Пекин: Металлургическая промышленность, 2009. [Huang Lihuang. Gold and silver mining technique. Beijing, Metallurgical Industry Press, 2009 (in Russian)]

[5] Guangxi Senhe High Technology Co., L., 30/10/2018. Jinchan gold ore dressing agent, leaching reagent, sodium cyanide replacement, s. 1. https:/jinchan.en.ecplaza.net/products/jinchan-gold-ore-dressingagentleaching-reagentsodium_4092507 
[6] Aylmore M.G. and Muir D.M. Thiosulfate leaching of gold-a review. Minerals Engineering, 2001, 14(2), 135-174.

[7] Breuer P. and Jeffrey. Thiosulfate leaching kinetics of gold in the presence of copper and ammonia. Minerals Engineering, 13(10), 1071-1081.

[8] Grosse A.C., Dicinoski G.W., Shaw M.J. and Haddad P.R. Leaching and recovery of gold using ammoniacal thiosulfate leach liquors (a review). Hydrometallurgy, 2003, 69(1), 1-21.

[9] Ha V.H., Lee J.-c., Jeong J., Hai H.T. and Jha M.K. Thiosulfate leaching of gold from waste mobile phones. Journal of Hazardous Materials, 2010, 178(1), 1115-1119.

[10] Lu Chaofei, Dan Xiaoye, Yun Yaxin, Ju Yonghui, Zhang Tao, Wang Yibing, Que Xiaofeng, Kang Jihong. Extraction of gold from concentrates with the environmentally friendly Jin chan leaching agent. Gold, $2014(5)$.

[11] Beyuo M., Abaka-Wood G.B., Asamoah R.K., Kabenlah A. and Amankwah R.K. A Comparative Study of Sodium Cyanide and Jinchan TM Gold Leaching Reagents: A Case Study at Goldfields Ghana Limited. 4th UMaT Biennial International Mining and Mineral Conference, 2016, pp. MR195-199.

[12] Плаксин И.Н. Металлургия благородных металлов. М.: Металлургиздат, 1958. 338 с. [Plaksin I. N. Metallurgy of precious metals. Moscow, Metallurgizdat, 1958. 338 p. (in Russian)].

[13] Масленицкий И.Н., Чугаев Л.В. Металлургия благородных металлов. М.: Металлургия, 1972. 367 c. [Maslenitskiy I. N., Chugaev L. V. Metallurgy of precious metals. Moscow, Metallurgy, 1972. 367 p. (in Russian)].

[14] Лодейщиков В.В., Игнатьев К. Д. Ращиональное использование серебросодержащих руд. М.: Недра, 1973. 224 с. [Lodeyshchikov V. V., Ignatiev K. D. Rational use of silver-bearing ores. Moscow, Nedra, 1973. 224 p. (in Russian)]

[15] Лодейщиков В.В. Технология извлечения золота и серебра из упорных руд. Иркутск: ОАО «Иргиредмет», 1999. 31 с. [Lodeyshchikov V.V. Technology for the extraction of gold and silver from refractory ores. Irkutsk, JSC «Irgiredmet», 1999. 31 p. (in Russian)] 